\title{
La parlamentarización de los sistemas presidencialistas y los derechos políticos de presidentes democráticamente elegidos: una visión desde los derechos humanos
}

\author{
The parlamentarization of presidential systems and the political rights \\ of presidents democratically elected: one vision from the human rights
}

\author{
Ana Claudia Santano ${ }^{1}$ \\ Centro Universitario Autónomo de Brasil-Unibrasil \\ anaclaudiasantano@yahoo.com.br.
}

\author{
Luis Antonio Corona Nakamura ${ }^{2}$ \\ Universidad de Guadalajara \\ l.corona@triejal.gob.mx.
}

\begin{abstract}
1 Profesora del programa de posgrado en Derechos Fundamentales y Democracia, del Centro Universitario Autónomo de Brasil, UniBrasil, en Curitiba, Paraná, Brasil. Doctora y maestra en Ciencias Jurídicas y Políticas por la Universidad de Salamanca, España. Estancia postdoctoral en la Universidad Externado, de Colombia y en la PUCPR, Brasil. Profesora de derecho constitucional, electoral y parlamentario en diversos cursos de grado y posgrado en Brasil y en el exterior.

2 Licenciatura y Maestría en Derecho por la Universidad de Guadalajara, Doctorado en Derecho por la Universidad Autónoma de Aguascalientes. Maestría en Derecho en Derecho Electoral por el Instituto Prisciliano Sánchez. Diplomados en Política Internacional Comparada y en Derecho Electoral, por la Universidad de Guadalajara. Profesor en los programas de licenciatura, maestría y doctorado (todos en derecho) de la Universidad de Guadalajara. Diversas publicaciones de artículos y capítulos de libro en materia constitucional, electoral y derechos humanos en revistas y libros en México y otros países. Miembro del Sistema Nacional de Investigadores (SNI nivel I) CONACYT. Perfil PRODEP. Fue Magistrado Electoral del Tribunal Electoral en Jalisco, Secretario de Estudio y Cuenta del Tribunal Electoral de la Federación; actualmente Director del Instituto de Investigación y Capacitación en Derechos Humanos de la CEDHJ.
\end{abstract}

Artículo recibido el 07.04.2020 y aceptado para su publicación el 13.08.2020. 
Resumen: Uno de los temas que se encuentran en la actual agenda latinoamericana es referente a los juicios políticos involucrando presidentes democráticamente elegidos. Los casos de Honduras, Paraguay y Brasil ilustran un desafío contemporáneo de cómo interpretar los derechos políticos dentro de un marco constitucional que equilibre el control de poder del mandatario y la soberanía popular. La principal cuestión es si un juicio con perfil político, aunque realizado dentro de las formalidades legales, no podría violar los derechos políticos que se encuentran en los tratados internacionales de derechos humanos, en un continente todavía carente de consolidación democrática. En este sentido, por medio de una revisión bibliográfica crítica deductiva, se formula una respuesta a esta cuestión a partir de lo que se conoce por proceso de parlamentarización de los sistemas presidencialistas en América Latina, avanzando para una interpretación de los derechos políticos tanto en la Declaración Americana como en la Convención, para luego hablar sobre la eventual necesidad de coaliciones para el ejercicio del mandato de presidente y la relación de esto con la soberanía popular.

Palabras clave: Juicios Políticos; Derechos Políticos; Parlamentarización; Presidencialismo; Impeachment.

Abstract: One of the most polemic issues involving presidential systems in the Latin-American political landscape is the possibility of impeachment of presidents democratically elected. Cases happened in Honduras, Paraguay and Brazil illustrate the challenge of how to understand the political rights in a constitutional framework which can balance the necessary control of power of presidents and popular sovereignty. The main question is if an impeachment, being a political procedure, even if celebrated according to the legal rules, would not violate presidents' political rights stated by international treaties of human rights in a continent that still suffers with lack of democracy consolidation. In this sense, through a bibliographic critical deductive review, it is tried to answer this question, having as a starting point the parlamentarization processes of presidential systems in Latin America, following by the interpreting of political rights concerning the American Declaration and Convention of Human Rights. Then, it will argue about the eventual need of coalitions to the exercise of the mandate and its relation with popular sovereignty.

Keywords: Political Judgments; Political Rights; Parlamentarization; Presidentialism; Impeachment. 


\section{Introducción}

En 2017, la Corte Interamericana de Derechos Humanos realizó una consulta pública sobre un cuestionamiento hecho por la Comisión Interamericana de Derechos Humano ${ }^{3}$, en lo que se refiere a los juicios políticos de presidentes democráticamente elegidos. Al solicitar el parecer consultivo, la Comisión destaca el gran avance de la democracia en el continente americano después de un largo periodo de golpes militares o usurpación violenta del poder (refiriéndose a la tercera ola democratizadora ${ }^{4}$ ). Sin embargo, la solicitud para un parecer se fundamenta en el hecho de que, en los últimos años, hubo episodios en los que se produjeron cambios en el Poder Ejecutivo en circunstancias que pusieron en duda la legitimidad o el principio de la separación de poderes en este proceso, contando con juicios políticos de presidentes elegidos, en condiciones que suscitaron fuertes cuestionamientos sobre las salvaguardias al debido proceso. ${ }^{5}$

Con esto, para que se pueda posibilitar una mayor participación social en la construcción de su posición ${ }^{6}$, fueron formuladas preguntas que podrían ser también objeto de contestación por parte de la sociedad civil. ${ }^{7}$ Una de ellas cues-

3 La potestad consultiva de la Corte Interamericana consta en el art. 64 de la Convención Americana de Derechos Humanos, a saber: "Artículo 64. 1. Los Estados miembros de la Organización podrán consultar a la Corte acerca de la interpretación de esta Convención o de otros tratados concernientes a la protección de los derechos humanos en los Estados americanos. Asimismo, podrán consultarla, en lo que les compete, los órganos enumerados en el capítulo X de la Carta de la Organización de los Estados Americanos, reformada por el Protocolo de Buenos Aires. 2. La Corte, a solicitud de un Estado miembro de la Organización, podrá darle opiniones acerca de la compatibilidad entre cualquiera de sus leyes internas y los mencionados instrumentos internacionales."

4 Huntington, (1992), pp. 3 y ss.

5 A su vez, la Corte decidió no continuar el trámite de la solicitud de opinión consultiva presentada por la Comisión Interamericana de Derechos Humanos, por entender que ya existe una línea jurisprudencial sobre garantías judiciales, protección judicial, y juicios políticos que podría dar insumos a las consultas de la Comisión y que cualquier pronunciamiento debe ser hecho sobre un caso contencioso que pueda venir. (Resolución de la Corte Interamericana de Derechos Humanos, de 29 de Mayo de 2018, con un voto disidente del Juez L. Patricio Pazmiño Freire).

6 Se puede aquí hacer un paralelo sobre la tesis de la sociedad abierta de intérpretes, de Peter Häberle. En esta tesis, el autor entiende que en el proceso de interpretación constitucional, todos los órganos estatales, potencias públicas, ciudadanos y grupos están muy vinculados, no siendo posible establecerse un listado cerrado o numerus clausus de intérpretes. Esto contrapone a la idea entonces tenida de que la interpretación constitucional era algo reservado a una sociedad cerrada, intérpretes jurídicos y participantes formales del proceso de interpretación constitucional. En el caso, se trata de la Declaración Americana y de la Convención Americana de Derechos Humanos, como su fuera una constitución objeto de la tesis de Häberle. (HÄBERLE, (2002).

7 El procedimiento está previsto en el art. 73 del Reglamento Interno de la Corte Interamericana de Derechos Humanos: "Artículo 73. Procedimiento. 1. Una vez recibida una solicitud de opinión consultiva, el 
tionaba sobre las hipótesis en las que un juicio político de un(a) presidente(a) democráticamente elegido(a), realizado por el Poder Legislativo, podría violar sus derechos políticos a la luz de la normativa interamericana de Derechos Humanos. ${ }^{8}$

Dicha indagación trae diversos elementos que deben forzosamente ser tomados en cuenta en este análisis que aquí se propone. El primero de ellos es que se asume que hay la elección democrática y constitucional de un(a) presidente(a) gozando, por lo tanto, de legitimidad para ejercer su mandato para el que fue elegido. Aquí se debe también añadir el factor de la soberanía popular que, expresándose por medio de un proceso electoral válido, optó por un nombre específico para ser el jefe de gobierno. Se trata de un modelo electoral presidencialista, nominal dentro del contexto latinoamericano, tendiente al personalismo, lo que puede llevar al cuestionamiento sobre la existencia de la influencia del partido que lanzó la candidatura en el resultado.

El segundo elemento es que se asume que el juicio tiene una fuerte carga política en su naturaleza, originada de un mecanismo de control también político introducido en un sistema presidencialista de gobierno. Esto, sin embargo, no evita o no impide que exista control judicial sobre sus procedimientos, para que se protejan las garantías constitucionales de defensa del que está siendo sometido a este juicio.

El tercer elemento es que, aunque sea un juicio político, el caso es que la persona que responde ante él es tenida solamente como acusada, no impidiendo que $a$ posteriori exista alguna palabra del Poder Judicial, en el sentido de garantizar un

Secretario transmitirá copia a todos los Estados miembros, a la Comisión, al Consejo Permanente a través de su Presidencia, al Secretario General y a los órganos de la OEA a cuya esfera de competencia se refiera el tema de la consulta, si fuere del caso. 2. La Presidencia fijará un plazo para que los interesados remitan sus observaciones escritas. 3. La Presidencia podrá invitar o autorizar a cualquier persona interesada para que presente su opinión escrita sobre los puntos sometidos a consulta. Si la solicitud es de aquéllas a que se refiere el artículo 64.2 de la Convención, lo podrá hacer previa consulta con el agente. 4. Una vez concluido el procedimiento escrito, la Corte decidirá si considera conveniente la realización del procedimiento oral y fijará la audiencia, a menos que delegue este último cometido en la Presidencia. En el caso de lo previsto en el artículo 64.2 de la Convención se hará previa consulta con el Agente."

8 Así es la pregunta formulada en el apartado II, f: "II - Sobre juicios políticos contra presidentes/as de-

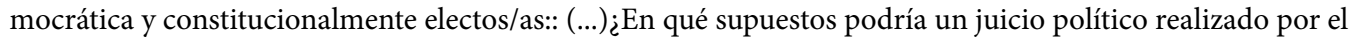
Poder Legislativo contra Presidentes/as democrática y constitucionalmente electos/as, ser violatorio de los derechos políticos de la persona enjuiciada a la luz del Artículo 23 de la Convención Americana sobre Derechos Humanos y Artículo XX de la Declaración Americana de los Derechos y Deberes del Hombre?”. Todas las preguntas sometidas a la opinión consultiva están disponibles en: $<$ https://www.oas.org/es/cidh/docs/ pdfs/2017/Solicitud-OpinionConsultiva-JuicioPolitico.pdf> Fecha de consulta: o6 abr. 2019. 
juicio imparcial y justo, así como observancia al debido proceso, al contradictorio y a la amplia defensa.

El cuarto elemento es que el juicio político es realizado por el Poder Legislativo, también compuesto por miembros democráticamente elegidos, pero por otro sistema electoral, muchas veces siendo el proporcional en el contexto latinoamericano, en el que los partidos políticos son preponderantes en la dirección de su actuación dentro de las casas legislativas.

A partir de ello, y entendiendo que la temática es importante ante los ocurridos en distintos países, se propone aquí un ensayo sobre si un juicio con perfil político, aunque realizado con aires de formalidades legales, no podría violar los derechos políticos que se encuentran en los tratados internacionales de derechos humanos de presidentes elegidos democráticamente. Para tanto, por medio de una revisión bibliográfica crítica deductiva, el artículo trae, en un primer momento, una interpretación de lo que se conoce por el proceso de parlamentarización de los sistemas presidencialistas en América Latina, para avanzar sobre una lectura de los derechos políticos tanto en la Declaración Americana como en la Convención. Luego, se aborda el tema de la eventual necesidad de coaliciones para el ejercicio del mandato de presidente y sus reflejos en sus derechos políticos y en juicios políticos, y la relación de esto con la soberanía popular, ante los conflictos existentes entre el Poder Legislativo y el Jefe del Ejecutivo. Al final, se concluye con algunos apuntamientos sobre dicha parlamentarización y el ejercicio de derechos políticos.

Cabe subrayar que aquí no se abordará ningún país en específico, mencionando uno $\mathrm{u}$ otro solamente para basar los argumentos aportados. Tampoco se profundizará en la jurisprudencia de la Corte Interamericana, aunque se utilizará los derechos políticos contenidos en tratados internacionales como soporte del raciocinio aquí trabajado.

\section{El proceso de parlamentarización de los sistemas presidencialistas en América Latina}

Muchos países latinoamericanos optaron - por diversas razones - por el presidencialismo como sistema de gobierno. Dicho sistema se caracteriza, según La Palombara, por (i) un presidente, que ejerce funciones de jefe de Estado y de gobierno a la vez, lo que lo hace unitario, independiente del Poder Legislativo y, por lo tanto, no dependiente de este para su existencia o supervivencia; (ii) independencia de 
los poderes Legislativo y Ejecutivo, tanto del punto de vista electoral, como desde el político, no estando el primero obligado a aprobar proyectos de ley que vengan desde el Ejecutivo, pudiendo este vetar los proyectos de ley que vengan desde el Congreso o Parlamento; (iii) el presidente tiene facultad de elección de nombres para su gobierno; (iv) el Ejecutivo puede apelar directamente al pueblo por medio de plebiscitos y de referendos; (v) el Legislativo puede juzgar y remover el presidente; (vi) el presidente puede presentar iniciativas de ley o designar alguien de su gabinete para que lo haga, así como puede preparar el presupuesto; (vii) el pueblo elige directamente el presidente como un "líder". 9

Por otro lado, el sistema parlamentarista de gobierno, que tiene origen distinto del presidencialismo, tiene otros elementos que lo caracterizan: (i) los miembros del gabinete (en el caso, el Poder Ejecutivo) son también miembros del Parlamento (Poder Legislativo); (ii) el gabinete está integrado por los dirigentes del partido mayoritario o por los jefes de los partidos que conforman la mayoría parlamentaria; (iii) el Poder Ejecutivo es doble, porque hay un jefe de Estado que tiene principalmente funciones de representación y de protocolo, y un jefe de gobierno, que coordina la administración y el gobierno; (iv) en el gabinete, existe una persona que tiene supremacía, el primer ministro; (v) el gabinete restará formado siempre y cuando haya el apoyo de la mayoría parlamentaria; (vi) la administración pública está encargada al gabinete, pero este se encuentra sometido a la constante supervisión del Parlamento; (vii) existe entre el Parlamento y el gobierno un control mutuo, siendo que el primero puede exigir responsabilidad política al gobierno, considerando o uno de sus miembros, o el gabinete entero; o el Parlamento puede negar el voto de confianza u otorgar un voto de censura al gabinete, obligándolo a que renuncie. Asimismo, el gobierno también tiene mecanismos de control del Parlamento, ya que tiene atribuciones de jefe de Estado, pudiendo disolverlo, convocando nuevas elecciones. Es por medio de este nuevo procedimiento electoral que el pueblo declarará su apoyo al gobierno o al Parlamento. ${ }^{10}$

Ante esto, se verifica que, en los sistemas presidencialistas, no hay la previsión de un "voto de confianza" o un "voto de censura" que pueda someter el gobierno (el presidente aquí) al Parlamento, así como no puede el presidente disolver el Parlamento. Más allá de eso, el presidente no hace parte del Congreso y, al menos

9 La Palombara, (1974), p. 198-199. Traducción libre.

10 CARPIZO, (2006), p. 60. 
teóricamente, sus secretarios tampoco deberían hacerlo, aunque es relativamente común en algunos países que eso ocurra.

Sin embargo, principalmente en los casos latinoamericanos, es importante destacar una característica de los sistemas presidencialistas: la posibilidad de que los vice-presidentes sean de un partido distinto que el del presidente, o incluso que de la mayoría del Parlamento. Puede, además, conformarse la situación de que el propio presidente sea de un partido que no tiene la mayoría parlamentaria, lo que puede tener reflejos en su gobernabilidad, pero no debería impactar el ejercicio y permanencia en su mandato.

En este sentido, es importante subrayar que, en los sistemas presidencialistas, por haber elecciones separadas para Presidente y Parlamento, hay lo que Juan Linz denominó de legitimidad democrática dual, es decir, el pueblo, por medio del voto, eligió la figura del presidente de forma apartada que la de los representantes en el Congreso. Ambos, por lo tanto, gozan de status democrático directo que, con base en la soberanía popular, debe ser respetado. Por otro lado, hay también la rigidez del sistema, ya que ambos son elegidos para un periodo fijo de tiempo, debiendo permanecer el presidente en el cargo independientemente de la voluntad del Congreso, cuya existencia, a su vez, también es independiente de las intenciones del presidente. ${ }^{11}$

Hay, en este sentido, una rigidez que impregna no sólo el ejercicio de las funciones de cada uno de los poderes, sino también en el encaje de cada uno dentro del Estado, no debiendo haber interferencias entre uno y otro, con algunas raras excepciones y, en estos casos, siempre amparados por los controles políticos dispuestos en la Constitución.

Con todo, no se puede negar que existe una tendencia en los sistemas presidencialistas, principalmente en América Latina, a introducir mecanismos parlamentarios en los sistemas presidencialistas, algo que crece en los últimos tiempos llegando, incluso, a distintas modalidades de censura y de falta de confianza al gobierno o a los ministros individualmente, o también a la disolución del Congreso,

11 LiNZ, (1994), p. 6. 


\section{como las previstas en la Constitución peruana ${ }^{12} \mathrm{y}_{\text {uruguaya }^{13}}$, por ejemplo, aunque}

12 Artículo 134.- El Presidente de la República está facultado para disolver el Congreso si éste ha censurado o negado su confianza a dos Consejos de Ministros.

El decreto de disolución contiene la convocatoria a elecciones para un nuevo Congreso. Dichas elecciones se realizan dentro de los cuatro meses de la fecha de disolución, sin que pueda alterarse el sistema electoral preexistente. No puede disolverse el Congreso en el último año de su mandato.

Disuelto el Congreso, se mantiene en funciones la Comisión Permanente, la cual no puede ser disuelta. No hay otras formas de revocatoria del mandato parlamentario.

Bajo estado de sitio, el Congreso no puede ser disuelto.

13 Artículo 148. La desaprobación podrá ser individual, plural o colectiva, debiendo ser pronunciada en cualquier caso, por la mayoría absoluta de votos del total de componentes de la Asamblea General, en sesión especial y pública. Sin embargo, podrá optarse por la sesión secreta cuando así lo exijan las circunstancias.

Se entenderá por desaprobación individual la que afecte a un Ministro, por desaprobación plural la que afecte a más de un Ministro, y por desaprobación colectiva la que afecte a la mayoría del Consejo de Ministros.

La desaprobación pronunciada conforme a lo dispuesto en los incisos anteriores, determinará la renuncia del Ministro, de los Ministros o del Consejo de Ministros, según los casos.

El Presidente de la República podrá observar el voto de desaprobación cuando sea pronunciado por menos de dos tercios del total de componentes del Cuerpo.

En tal caso la Asamblea General será convocada a sesión especial a celebrarse dentro de los diez días siguientes.

Si en una primera convocatoria la Asamblea General no reúne el número de Legisladores necesarios para sesionar, se practicará una segunda convocatoria, no antes de veinticuatro horas ni después de setenta y dos horas de la primera, y si en ésta tampoco tuviera número se considerará revocado el acto de desaprobación.

Si la Asamblea General mantuviera su voto por un número inferior a los tres quintos del total de sus componentes, el Presidente de la República, dentro de las cuarenta y ocho horas siguientes podrá mantener por decisión expresa, al Ministro, a los Ministros o al Consejo de Ministros censurados y disolver las Cámaras.

En tal caso deberá convocar a nueva elección de Senadores y Representantes, la que se efectuará el octavo domingo siguiente a la fecha de la referida decisión.

El mantenimiento del Ministro, Ministros o Consejo de Ministros censurados, la disolución de las Cámaras y la convocatoria a nueva elección, deberá hacerse simultáneamente en el mismo decreto.

En tal caso las Cámaras quedarán suspendidas en sus funciones, pero subsistirá el estatuto y fuero de los Legisladores.

El Presidente de la República no podrá ejercer esa facultad durante los últimos doce meses de su mandato. Durante igual término, la Asamblea General podrá votar la desaprobación con los efectos del apartado tercero del presente artículo, cuando sea pronunciada por dos tercios o más del total de sus componentes.

Tratándose de desaprobación no colectiva, el Presidente de la República no podrá ejercer esa facultad sino una sola vez durante el término de su mandato.

Desde el momento en que el Poder Ejecutivo no dé cumplimiento al decreto de convocatoria a las nuevas elecciones, las Cámaras volverán a reunirse de pleno derecho y recobrarán sus facultades constitucionales como Poder legítimo del Estado y caerá el Consejo de Ministros.

Si a los noventa días de realizada la elección, la Corte Electoral no hubiese proclamado la mayoría de los miembros de cada una de las Cámaras, las Cámaras disueltas también recobrarán sus derechos.

Proclamada la mayoría de los miembros de cada una de las nuevas Cámaras por la Corte Electoral, la Asamblea General se reunirá de pleno derecho dentro del tercer día de efectuada la comunicación respectiva.

La nueva Asamblea General se reunirá sin previa convocatoria del Poder Ejecutivo y simultáneamente cesará la anterior.

Dentro de los quince días de su constitución, la nueva Asamblea General, por mayoría absoluta del total de sus componentes, mantendrá o revocará el voto de desaprobación. Si lo mantuviera caerá el Consejo de Ministros. 
cuenten con muy difíciles requisitos o de la imposibilidad virtual de realización.

Dicha incorporación de mecanismos parlamentarios en los sistemas presidencialistas atiende a una necesidad de racionalizar ambos los sistemas, tanto en términos de gobernabilidad como de estabilidad. Como es sabido, el sistema presidencialista puede, eventualmente y debido a la separación entre el Poder Ejecutivo y el Legislativo, carecer de gobernabilidad. Esto porque la construcción de acuerdos políticos puede ser más compleja, a depender del número de partidos en el Congreso o incluso del perfil del presidente, teniendo él mucho más discrecionalidad para gobernar. Ya en el sistema parlamentario, puede haber problemas en su estabilidad, ya que ambos poderes Ejecutivo y Legislativo dependen uno del otro para mantenerse. En el caso de que exista algún factor que desequilibre dicha relación, el resultado comúnmente puede ser la disolución de las Cámaras, o el voto de censura.

Diego Valadés abordó la cuestión de la parlamentarización de los sistemas presidencialistas, que desde un primer momento la distingue de la parlamentarización de los sistemas constitucionales. En esta, el autor entiende que toda la estructura constitucional del poder político tiende a adecuarse al sistema parlamentario, que es incorporado de manera inmediata o gradual, para la sustitución del sistema vigente, que puede ser el presidencial o el tradicional. Ya la parlamentarización de los sistemas presidencialistas mantiene la estructura existente, aunque añade algunas instituciones de control político, incluso cambiándolas, de origen parlamentario. ${ }^{14}$

En este sentido, si el control político aplicado sobre el jefe del ejecutivo - en el caso, el presidente -,puede tener naturaleza parlamentaria o contar con alguna institución para ejercer dicho control que tiene este perfil, se puede hablar en parlamentarización de un sistema presidencialista, pero quizás no en una legitimación constitucional para ello, considerando que no se objetiva cambiar la estructura del sistema de gobierno, sino solamente aplicar medidas parlamentaristas sobre él.

A partir de esto, no se rechaza la hipótesis de que la racionalización de un sistema presidencialista específico pueda venir vía control político de naturaleza parlamentaria. Hay autores, de hecho, que entienden que es mejor modificar el comportamiento de un sistema de que sustituirlo como un todo. Con todo, cabe

Las Cámaras elegidas extraordinariamente, completarán el término de duración normal de las cesantes. 14 Valadés, (2011), pp. 5-6. 
la advertencia de que es posible que los defectos de un sistema, verificados en un momento determinado, hayan sido sus virtudes y ventajas en otro periodo. ${ }^{15}$

Dentro de esta perspectiva, los juicios políticos ya fueron pensados justamente como controles políticos, no exactamente en su aspecto parlamentario, sino más bien como un mecanismo que posibilita poner freno al jefe del Ejecutivo que haya perdido su legitimidad durante su mandato. Sin embargo, eso no vino sin polémicas. Mario D. Serrafero trae la distinción de pensamientos entre autores más clásicos como Lord Blackstone y Edmund Burke. El primero entendía que los juicios políticos deberían ser aplicados solamente ante la violación de una ley muy bien establecida. Ya el segundo sostenía, en cambio, que el impeachment debía incluir también los casos de abuso de autoridad y abuso de confianza de los funcionarios, como una herramienta de control político. ${ }^{16}$ A partir de entonces, la doctrina se divide en considerar el juicio político como una opción para tratar sobre la responsabilidad política de los jefes de ejecutivo, o que es algo únicamente aplicable en casos de delitos graves. ${ }^{17}$

Sin embargo, es cierto que, aunque se entienda que, en sistemas presidencialistas se ejercen controles políticos sin responsabilidad, estos son, de hecho, menos contundentes que los de perfil parlamentarista, lo que los pone dentro del marco constitucional para contener el ejercicio del poder dentro de los límites entonces previstos. Es esta una de las principales fundamentaciones de este sistema de gobierno, ya que el Jefe del Ejecutivo es elegido por sufragio popular.

En este sentido, sería natural defender que, en un sistema presidencialista, al contrario de lo que ocurre con el parlamentario, los controles políticos que inciden deben estar explícitos en la Constitución y en un orden institucional, lo que abarca la publicidad de los actos de gobierno y el control de la administración, pero que no parece haber espacio para controles políticos que atiendan a la lógica de la mayoría-minoría, como ocurre en el parlamentario. Se trata aquí lo que Dworkin entiende como siendo el juicio político por el impeachment como un "arma nuclear" que debe ser utilizada tan solamente en casos de gravedad elevada, porque da a los parlamentarios muchos poderes que pueden desestructurar los sistemas constitucionales. Si su uso fuera adoptado por los sistemas presidencialistas - como eventualmente se puede pretender al poner lado a lado con

15 VAladés, (2005), p. 57.

16 Serrafero, (1996), p. 138.

17 Nogueira Alcalá, (1985). 
el voto de censura - según Dworkin, dicho poder puede ser utilizado de forma abusiva, en contra de la democracia, ${ }^{18}$ ya que un juicio político va, seguramente, a alterar la conformación de las fuerzas partidarias después de concluido. ${ }^{19}$

Así, los controles políticos aplicados en uno u otro sistema también atienden a la propia forma de elección del jefe de gabinete. Mientras que en los sistemas parlamentarios la elección del jefe de gobierno es realizada por vía política, puede también tener su término final por medio de un mecanismo político, debiendo estar previsto en la Constitución solamente la existencia de esta posibilidad, sin mayores rigores en sus requisitos. Ya en los sistemas presidencialistas, como la forma de elección del presidente viene por medio del voto popular, con legitimación democrática, solamente la Constitución podrá determinar cómo, cuándo y quien tiene igual legitimidad para destituirlo y eso va a ser determinante para la validez de todo el juicio político, porque la legalidad estricta es la que puede, en un primer momento, demostrar que las instituciones de aquél país están funcionando y que hacen debidamente su tarea de control. Aunque ciertos juicios políticos puedan ser entendidos como controles políticos en los moldes parlamentarios, estos no se confunden, ya que dichos juicios deben ocurrir siempre y dentro del marco constitucional determinado, sin utilizarse motivos "creativos" de interpretación de causales de los impeachments.

\section{Como interpretar los derechos políticos tanto en la Declaración Americana como en la Convención}

La Declaración Americana de Derechos Humanos dispone, en su art. XX, que toda persona legalmente capacitada tiene el derecho de tomar parte en el gobierno de su país, sea directa o indirectamente, por medio de representantes, así como de participar de las elecciones, por medio del voto secreto, de forma genuina, periódica y libre. Se afirman, aquí, la soberanía popular y los moldes de democracia que se consideran imprescindibles para los derechos humanos.

Dicha protección a los derechos políticos se repite en la Convención Americana sobre los Derechos Humanos, en su art. 23, garantizando a todos los ciudadanos el derecho de participar en la dirección de los asuntos públicos, directamente o por medio de representantes libremente elegidos, de votar y de ser votado en

18 DWORKIN (1999), p. 1.

19 Helmke (2017), p. 71. 
elecciones periódicas auténticas, realizadas por sufragio universal e igual, por voto secreto que asegure la libre expresión de la voluntad de los electores, y de tener acceso, en condiciones generales de igualdad, a las funciones públicas de su país. Aún, el Pacto de San José establece que una ley puede regular el ejercicio de los derechos políticos del art. 23, basándose exclusivamente por motivos de edad, nacionalidad, residencia, idioma, instrucción, capacidad civil o mental, o condena, por juez competente, en proceso penal, algo que está causando algunos conflictos entre la posición de la Comisión y de la Corte Interamericana de Derechos Humanos y los ordenamientos jurídicos de algunos Estados parte de la Convención. En este sentido, tanto la Comisión como la Corte ya tuvieron oportunidad de manifestarse sobre dichas prohibiciones en el caso Yatama vs. Nicaragua (decisión de o1 de septiembre de 2011); Gustavo Petro Urrego vs. Colombia (con medida cautelar impuesta por la Comisión desde 2014, pero con medidas desestimadas por la Corte, en 2019), y otros. En estos casos, lo que se debate es el derecho de ser elegido y de permanecer elegido, ante decisiones de órganos que no se constituyan en una condena, por juez competente, en proceso penal. ${ }^{20}$

Ambos los dispositivos legales abordan la libertad de presentarse como candidato, ya que ésta es, notoriamente, una forma de participación en la política. Junto a ello, parece vital entender que entra en el contenido de los derechos políticos listados el derecho a tener acceso al mandato para el que la persona fue democráticamente elegida, teniendo, dentro del marco constitucional del país, libertad para su ejercicio. En este sentido, la Corte Interamericana de Derecho Humanos ya se pronunció sobre la incidencia del art. 23 de la Convención también sobre el acceso y ejercicio de los mandatos electivos. Los Estados, aquí, deben proteger el derecho de sufragio pasivo, que también abarca la concreta adopción de medidas efectivas para el pleno ejercicio del mandato, garantizando las condiciones necesarias para ello, como restolvió en el caso Manuel Cepeda Vargas vs. Colombia (decisión de 26 de mayo de 2010). ${ }^{21}$

20 Para un análisis más detallado sobre esos casos, vid., por todos: AmaYa y LoiAnNo (2014); y AmayA (2016).

21 Parágrafo 172: "La Corte considera que la Convención protege los elementos esenciales de la democracia, entre los que se encuentra "el acceso al poder y su ejercicio con sujeción al Estado de Derecho". Entre otros derechos políticos, el artículo 23 de la Convención protege el derecho a ser elegido, el cual supone que el titular de los derechos tenga la oportunidad real de ejercerlos, para lo cual debe adoptar medidas efectivas para garantizar las condiciones necesarias para su pleno ejercicio". 
Con esto, se tiene que el límite del ejercicio y de la actuación del electo en el mandato debe constar en la Constitución del país que se trata, así como los posibles controles que indicen sobre el mandatario. No hay, o no debería haber, espacios discrecionales para la interferencia en el ejercicio del mandato por el Presidente democráticamente elegido, aunque se sepa que algunos de los mecanismos de control político, por tener esta naturaleza, podrán eventualmente ser accionados según criterios no exactamente positivados en la Constitución o en el ordenamiento jurídico. Dichos controles, según lo especificado por la Corte Interamericana, no pueden constituirse como barreras para el ejercicio de derechos políticos, sino que generen todo un ambiente para ejercerlos en su plenitud. Es decir, los controles no pueden ser amenazas o riendas en su actuación en el cargo.

Sin embargo, aunque los mecanismos de control político del jefe del Ejecutivo tengan mayor apertura justamente debido a su naturaleza y a la necesidad de cobrarles responsabilidad en el desarrollo de sus funciones, eso no significa, en ninguna hipótesis, que ellos puedan ser utilizados fuera del marco constitucional. Por lo tanto, la estricta legalidad y constitucionalidad de los procedimientos de control son vitales para la legitimidad de sus objetivos. De hecho, la estricta legalidad de juicios políticos es lo que es señalado por algunos estudiosos de que las instituciones funcionan debidamente y que eso demuestra la salud democrática, justamente porque trae la cultura de responsabilidad que todo presidente tiene que tener, ${ }^{22}$ aunque eso no evite que los impeachments sean utilizados por otras razones oportunistas.

\section{La eventual necesidad de coaliciones para el ejercicio del mandato de presidente y sus reflejos en sus derechos políticos y en juicios políticos}

Ya fue objeto de análisis el contenido que tanto la Declaración Americana de Derechos Humanos como la Convención atribuyen a los derechos políticos. En este sentido, consta expresamente el derecho de participar en la dirección de los asuntos públicos, directamente o por medio de representantes elegidos. Dentro de este entendimiento, debe ser considerado también el acceso al mandato conquistado por medio del sufragio libre y un procedimiento democrático, así como la libertad de su ejercicio, guardadas las limitaciones de perfil constitucional.

22 Carey (2008), pp. 91-122. 
Como también ya se ha mencionado, los sistemas parlamentarios se basan en controles políticos y, siendo así, los derechos políticos del Jefe del Ejecutivo se mantienen, aunque después de su renuncia o eventual voto de censura. Su cargo viene por medio de acuerdos políticos construidos por la mayoría del Parlamento $y$, de esta forma, también su mandato podrá sufrir algún tipo de control. Es decir, tanto el acceso al cargo como la libertad para ejercerlo también se someten a estos acuerdos políticos. Dicha dinámica no viola, prima facie, los derechos políticos de su titular, considerando que la naturaleza política de la decisión que lo mantiene o no en el poder no incumple reglas constitucionales o la soberanía popular, ya que el cargo no tiene legitimidad democrática directa.

En los sistemas presidencialistas, no se puede decir lo mismo. Hay, en primer lugar, la legitimación democrática del mandatario para la ocupación de su cargo como jefe de gobierno y de Estado, que no se someten a los acuerdos políticos de mayorías-minorías del momento. El hecho de haber sido elegido concede al titular del mandato plenos derechos de participar directamente de los asuntos públicos, así como el acceso al cargo y libertad para ejercerlo. Este conjunto de derechos políticos no está sometido a los arreglos políticos que eventualmente existían en el Congreso y que, en caso de estar, podrán violarlos en nombre de un movimiento contramayoritario que contraría la soberanía popular.

Es en este punto que, según la jurisprudencia de la Corte Interamericana de Derechos Humanos, hay parámetros a seguir para la garantía de dichos derechos, es decir, los Estados deben proteger el derecho de sufragio pasivo, que también abarca la concreta adopción de medidas efectivas para el pleno ejercicio del mandato, garantizando las condiciones necesarias para ello. Por lo tanto, hay una necesidad de protección que no se rinde a los acuerdos políticos, sino que debe haber medidas de garantías incluso en momentos en los que hay desacuerdos que produzcan tensiones entre el Poder Ejecutivo y el Legislativo.

En esta línea, el involucramiento de un presidente democráticamente elegido en un acuerdo político en el que no haya participado y que, debido a las diferencias políticas, termina siendo objeto de un juicio político que, eventualmente, culmine en su retirada del cargo, no hace parte del listado de controles políticos característicos del presidencialismo. El desacuerdo del Congreso o eventuales crisis entre los dos poderes, así, pueden comprometer el ejercicio del mandato del presidente y, consecuentemente, violar sus derechos políticos, impidiéndole participar de los asuntos públicos directamente, con el agravante de la violación 
de la soberanía popular que decidió por su nombre para ser el Jefe del Ejecutivo. Por otro lado, se puede afirmar que en el caso de que el jefe del Ejecutivo esté mal utilizando sus prerrogativas, aunque elegido legítimamente por voto popular, el impeachment se vuelve una alternativa de control, pero que no puede ser realizado sin observarse las reglas constitucionales existentes para ello.

Una de las dificultades de los sistemas presidencialistas latinoamericanos es, como ya se ha mencionado, la gobernabilidad. Situaciones de crisis entre el Ejecutivo y el Legislativo no son $\operatorname{raros}^{23}$, generando casi siempre problemas de gobernabilidad y, también no difícilmente, culminan en crisis presidenciales. Momentos así son la mayor representación de los "peligros del presidencialismo", según Anibal Pérez Liñan, ya que el intento de un poder de anular el otro, dentro de un marco de una constitución presidencialista que no ofrece mecanismos para ello, generan las condiciones "propicias" para un colapso en el régimen político. En este sentido, aunque se pueda afirmar que ni toda crisis presidencialista puede llevar a este temblor político, parece que, cuanto más autonomía el Parlamento tenga para cuestionar las acciones del Ejecutivo, más será posible una crisis de esta envergadura. ${ }^{24}$

Sin embargo, es cierto que los "hiperpresidencialismos" que representan la hegemonía del Poder Ejecutivo parecen poder promover más inestabilidad que los parlamentos, justamente por contar con más medios, recursos, poderes en general y que, en algunos casos, puede intentar imponer sus decisiones sobre el Poder Legislativo, ignorando el hecho de que los parlamentarios también gozan de legitimidad democrática y que tienen como función el control de la actuación del Ejecutivo dentro de la lógica de frenos y contrapesos. De hecho, en muchas

\footnotetext{
23 Según Aníbal Pérez Liñan, entre 1950 y 1996, América Latina continental sufrió 39 crisis presidencialistas: Argentina (durante las administraciones de Guido, en 1962, y Martínez de Perón, 1976), Bolivia (Natusch Busch, 1979; Siles, 1983; Paz Zamora, 1990), Brasil (Vargas, 1954; Luz, 1955; Café Filho, 1955; Goulart, 1964; Castello Branco, 1966; Costa e Silva, 1968; Geisel, 1977; Collor de Mello, 1992), Colombia (López Michelsen, 1977; Samper, 1996), Chile (Ibáñez, 1954; Allende, 1973), Ecuador (Velasco Ibarra, 1961; Arosemena, 1963; Velasco Ibarra, 1970; Febres Cordero, 1984 y 1987; Borja, 1990), El Salvador (Duarte, 1987), Guatemala (González López, 1957; Serrano, 1993), Honduras (Lozano, 1954; Suazo Córdova, 1985), Nicaragua (Chamorro, 1992), Panamá (Arias, 1951; Guizado, 1955; Robles, 1968; Delvalle, 1988), Paraguay (Chávez, 1954; Stroessner, 1959), Perú (Fujimori, 1992), Uruguay (Pacheco, 1969; Bordaberry, 1973) y Venezuela (Pérez, 1993) (Perez-Liñan, (2011), p. 3). En trabajo más reciente, el autor nombra los siguientes casos de impeachment: Fernando Collor (1992) y Dilma Rousseff (2016) en Brasil, Carlos Andrés Pérez (1993) en Venezuela, Abdalá Bucaram (1997) and Lucio Gutiérrez (2005) en Ecuador, Raúl Cubas (1999) y Fernando Lugo (2012) in Paraguay, y Otto Pérez Molina (2015) en Guatemala, además de 2 presidentes peruanos - Alberto Fujimori (2000) y Pedro Pablo Kuczynski (2018) - que renunciaron antes del juicio. (Perez-LiÑan, (2018), p. 2)..

24 Perez-Liñan, (2011), p. 5.
} 
situaciones que culminaron con impeachments, Pérez-Liñan señala que la instabilidad fue causada por presidentes hegemónicos y que la salida encontrada fue su destitución por parte del Parlamento. Este hecho es importante igual para este análisis que se propone porque, si no caben dudas de que hay un mal uso del instituto de los juicios políticos por parte de muchos parlamentos, también es importante tener en mente que los propios presidentes tienen su parte de contribución para el inicio de crisis políticas. ${ }^{25}$

Ante esto, la "armonía" de estos poderes puede traer la necesidad de coaliciones para que exista gobernabilidad, pero que, al final, pueden contribuir para la debilidad del gobierno del presidente de turno. Dichas coaliciones políticas son propias de los sistemas parlamentarios, estando, ocasionalmente, presentes en gobiernos presidencialistas. Sin embargo, tanto en uno como en el otro, las alianzas producen un importante cambio en la estructura de actuación de gobiernos, así como en los controles políticos existentes. Así, durante las coaliciones, es posible que una parte de estos controles previstos constitucionalmente pierda su normatividad y resten como meros enunciados, al mismo tiempo que puedan surgir otras formas de control, como parte de un acuerdo que fundamenta dicha coalición. Es decir, en lo que se refiere al control político, la coalición se transforma en un consenso que involucra la élite política, excluyendo la mayoría ciudadana. Según Valadés, al amenizar las discrepancias y simular o acentuar las coincidencias, se crean procedimientos de control que garantizan a los interlocutores el cumplimiento de compromisos asumidos cuando se realizó la coalición, sustituyendo a los que la Constitución dispone. Dichos procedimientos ya no son abordados ni siquiera en el ámbito parlamentario, sino que permanecen recluidos a los ambientes más íntimos de los gabinetes oficiales o, incluso, a los externos, como "recintos gastronómicos". ${ }^{26}$

De esta forma, se tiene que una coalición puede no solamente permitir la gobernabilidad de un presidente, manteniendo la dinámica Ejecutivo-Legislativo actica y sana ${ }^{27}$, sino que puede, también, en determinados casos, abrir espacio para desequilibrios en esta relación, haciendo del presidente un sumiso a las vo-

25 Perez-Liñan, (2018), p. 11.

26 VAladÉs, (2005), p. 54.

27 Esto puede ser llamado de presidencialismo de coalición, en el que coexisten el multipartidarismo, el sistema proporcional de elección de representantes y composiciones parlamentarias fragmentadas. Este arreglo institucional es bastante visible en el caso brasileño, por ejemplo, lo que agrava los riesgos de conflictos entre el Ejecutivo y el Legislativo. Sobre el tema, SCHIER, (2016a); SCHIER, (2016b); Abranches, (2018). 
luntades de los parlamentarios, que ignoran o se olvidan de su legitimidad democrática para el ejercicio de su mandato.

En este punto, no se puede desconocer la función de los partidos políticos. Cuando el eje del poder de gobierno se vuelca del Ejecutivo para el Legislativo en un sistema presidencialista, puede también ocurrir que las organizaciones partidistas parlamentarias extrapolen su función dentro de las casas legislativas para tener influencia o directamente decidir el comportamiento del presidente, utilizándose justamente como elemento de convencimiento o de coacción la posibilidad de que ocurra un juicio político previsto en la Constitución. Ante esto, hay una desvaloración (o ignorancia, desconsideración) del voto popular depositado en la elección del presidente para privilegiar las decisiones tomadas por los partidos y sus élites, dentro del Congreso.

Por otro lado, es sabido que los juicios políticos con mecanismos amparados por la Constitución y que involucran el concepto de crímenes de responsabilidad. El impeachment, como herramienta contundente de remoción del presidente, debe ser siempre de carácter excepcional. Si este juicio tiene como fundamento un delito (de responsabilidad), tiene naturaleza penal o casi penal, lo que lo somete a los estrictos límites de la tipicidad, y aunque dependa de cierto arreglo político para culminar en su resultado (la destitución del presidente) ${ }^{28}$, no se trata de un control político del Poder Legislativo sobre el Ejecutivo, ni debe ser así considerado o utilizado, pues es justamente esta rigidez en el presidencialismo - criticada por muchos - lo que impide de que sea cooptado por otros regímenes no democráticos, como los autoritarios. ${ }^{29}$

En este sentido, el uso y la interpretación del instrumento del impeachment no debe someterse a las mayorías de las coaliciones, ya que debe ser entendido dentro de un marco constitucional. Hay, en los juicios políticos, una situación de defensa de la Constitución que requiere dolo por parte del presidente y que su acto cometa un atentado, como un ataque y no de incumplimiento, al orden constitucional establecido. Es la Constitución que legitima la actuación del presidente en un sistema presidencialista y, aunque el juicio tenga la denominación de político (pues, al final, se debe alcanzar el número de votos necesario para su destitución), la instauración y desarrollo del procedimiento debe observar estrictamente el espacio concedido por el texto constitucional para ello. Así, crisis po-

28 CARPIZO, (2006), p. 67.

29 Perez-Liñan, (2011), p. 16. 
líticas económicas o incluso sociales no constituyen, y no deberían constituirse, por si mismas, en motivos que sugieren un impeachment..$^{30}$

Se verifica que, de esta forma, las coaliciones eventualmente necesarias a la gobernabilidad en un sistema presidencialista no deben prestarse a facilitar acuerdos políticos para el control indirecto del ejercicio del mandato del presidente, ni tampoco ser un canal de sumisión del jefe de gobierno a los albedríos de los parlamentarios. Cada cual goza de prerrogativas ante el Estado y de funciones dentro de sus respectivos poderes y que deben ser observadas y respetadas por ambos. De hecho, aquí el ensayo se suma a la posición de Agustín Gordillo, que entiende que el proceso de impeachment se asemeja a un proceso administrativo, incidiendo sobre él todas las garantías procesales y posibilidades de recursos judiciales ${ }^{31}$, algo que no es propio de controles políticos. ${ }^{32}$

\section{La soberanía popular ante los controles políticos ejercidos por el Poder Legislativo sobre el Jefe del Ejecutivo}

Ya fue mencionado que, en los sistemas presidencialistas, al contrario de lo que ocurre en los parlamentaristas, tienen legitimidad democrática dual tanto del presidente como de los miembros del Congreso. Así, la soberanía popular se manifiesta en la elección de los ocupantes de cada uno de los poderes, depositando por medio del voto su confianza en un determinado nombre. ${ }^{33}$

En este sentido, se puede considerar los juicios políticos como un mecanismo contramayoritario de gobierno. Esto porque, habida una situación en la que se configure una hipótesis de instauración de uno, el Congreso podrá decidir por la destitución del presidente, aunque él haya sido elegido con mayoría absoluta de los votos populares. ${ }^{34}$

Siendo así, se puede defender que el impeachment, cuando culmine en la destitución del presidente, siempre anulará los votos de los ciudadanos que le fueron destinados, así como volverá inhábil el proyecto de gobierno elegido por la mayoría del electorado. Es un instrumento que retira democracia de la democracia y es

30 Correia y Teixeira, (2018), pp. 65-80.

31 Gordillo, (2017), p. IX-14.

32 Sobre el tema, ZúÑIGA URBINA, (1993); ZÚÑIGA URBINA, (2006).

33 Por obvio que aquí restan variaciones del sistema electoral aplicable. Sin embargo, en cualquiera de ellos, el voto se hace necesario y presente para la elección de dichos representantes.

34 Tavares, (2016), p. 1058. 
esto lo que justifica su obligatoria excepcionalidad. En las palabras de André Ramos Tavares, "habrá tanto más democracia cuando mayor fuera la participación de los electores en la elección de uno de los nombres que los partidos políticos presentan". ${ }^{35}$

El juicio político no puede ser confundido como un mecanismo democrático, ni como herramienta normal y tampoco corriente, porque justamente lleva a la ciudadanía a cuestionar la función y el poder del voto. Su especialidad y singularidad de instauración puede, eventualmente, devolver democracia en situaciones limítrofes de ataque al orden institucional. Sin embargo, el impeachment difícilmente podrá promover democracia cuando sus fundamentos se alejan de la protección de la Constitución o incluso de la protección del mandato del presidente (no de su persona). Aquí, el impeachment puede servir para abrir espacios para golpes parlamentarios, y fue esto lo que motivó a la Corte Interamericana a provocar la comunidad internacional para pensar sobre la cuestión, más allá que los ejemplos de la realidad ya señalan un uso poco democrático de dicho mecanismo. ${ }^{36}$

Aquí es importante señalar que, en este trabajo, no se va a equiparar impeachment con lo que se viene denominando golpes parlamentarios. Aunque, según Pérez-Liñan, haya coincidencias de causas entre golpes militares y procesos de impeachment contemporáneos, el autor entiende que estirando el concepto ("conceptual stretching" de Sartori, citado por el autor) de "golpe" para ponerlo al lado de procedimientos legales de impeachment se puede generar un problema analítico, por permitir que se ignoren otros factores que tienen impacto aquí, como el tamaño del apoyo parlamentario del presidente en el Congreso. Además, el autor afirma que llamando a impeachments con legalidad poco fiable de golpe parlamentario, conlleva a considerar que fuerzas progresistas de los 90 (partidos y movimientos sociales) que fueron en contra de gobiernos neoliberales fueron, también, apoyadores de golpes, lo que puede incurrir, como mínimo, en injusticias hacia dichos actores. Por fin, equiparando estos conceptos, se puede incluso promover ideológicamente a los verdaderos golpes, como los militares, ya que aquellos que considerando los impeachments dentro de la legalidad igual pueden

35 Tavares, (2016), p. 1058. Traducción libre.

36 En este sentido, PéreZ-Liñan, (2009), pp. 336-337; ZúñIga Urbina, (2019), pp. 153-186. 
justificar así los golpes promovidos por militares, lo que no es para nada favorable dentro del tema democrático. ${ }^{37}$

Casos como descontento con la actuación del presidente, frustración con su mandato, o incluso daños y rupturas en la confianza sobre el proyecto gubernamental no deben (y no deberían) sugerir un juicio político, una vez que la democracia también tiene que ser considerada como un proceso de aprendizaje del electorado. El voto debe ser también destinado a premiar los gobernantes exitosos, así como castigar a los que no tuvieron un buen desempeño durante el mandato. Sin embargo, esta es una decisión que cabe únicamente a la ciudadanía, no al Congreso.

Es cierto que el juicio político, en la parte que toca al Poder Legislativo, la deliberación de los parlamentarios puede estar inmune a la intervención del Poder Judicial. Sin embargo, eso no significa que su origen, el leit motiv para su inicio pueda distanciarse de una tipificación objetiva y clara y que tampoco pueda desarrollarse fuera del marco del contradictorio y de la amplia defensa. No hay como consentir que razones para juicios políticos sean fruto de interpretaciones extensivas de reglas poco claras o que sean resultado de la discrecionalidad de los parlamentarios que no estén de acuerdo con la manera de gobernar del presidente. Eso puede causar una grieta profunda en un sistema político que ya se encuentra en crisis por el conflicto político entre los poderes. Además, dicha comprensión del impeachment es la que se adecua a la Convención Americana de Derechos Humanos tanto para el respeto a los derechos políticos del presidente como de sus derechos de defensa y garantías procesales, inherentes a todos. ${ }^{38}$

En la hipótesis de que se admita que se utilicen juicios políticos como forma de depurar crisis diversas en el gobierno, es probable que se permita la subversión de la lógica democrática por una autoritaria, ya que, además de permitir que un poder interfiera directamente en el otro ( $\mathrm{y}$ sin fundamento constitucional para ello), la decisión sobre quien ocupa o no el cargo de presidente puede pasar al Congreso, quitándosela de los ciudadanos. Cabe subrayar que el Parlamento no tiene esta función y no puede actuar de esta manera, considerando que se está tratando de un sistema presidencialista. Se podría, incluso, afirmar que dicho voluntarismo en la utilización del impeachment para la destitución del jefe del Ejecutivo es un

37 PÉReZ-Liñan, (2018), p. 8-9.

38 Perlingeiro (2018). 
claro atentado en contra de la Constitución, generando una situación exactamente opuesta a la que un juicio político objetiva proteger.

De hecho, Cass Sunstein sugiere tres pruebas para la verificación de la neutralidad de la utilización del mecanismo del impeachment, algo necesario en una república democrática: (i) que el procedimiento no sirva para que los perdedores subviertan el resultado de una elección legítima y que, por lo tanto, se tiene que preguntar si los apoyadores del impeachment seguirían apoyándolo si ellos concordaran con las políticas del presidente; (ii) que los opositores al impeachment observen si su apreciación de los hechos no están siendo distorsionados por su apoyo al presidente y; (iii) la adopción del velo de la ignorancia en lo que se refiere a quien está ocupando el cargo de presidente y la apreciación exclusiva de la demanda. ${ }^{39}$ Esto parece colaborar a que un juicio político no sirva como herramienta disponible a las mayorías o a los vientos, si no se basa en la defensa de la Constitución.

Cabe destacar que, aunque con la aproximación delineada de los sistemas parlamentarios y presidencialistas, es difícil justificar la equiparación del impeachment con el voto de confianza, ya que se destinan a fines distintos; tienen funciones opuestas y contrarias a la lógica del presidencialismo, que es justamente la de mantener la independencia del presidente ante el Congreso. Dicha equiparación resta todavía menos posible cuando no hay previsión constitucional sobre ello, pues, como ya se ha visto, el juicio político tiene como amparo y límites la Constitución, que incluso puede ser lacónica o contener silencios sobre el tema, pero que tiene un fundamento moral muy conectado con la democracia cuando esta establece los compromisos de la sociedad y del Estado. ${ }^{40}$ Además, cabe aquí la mención de que el sistema parlamentarista no exige violación a la Constitución para la destitución del Jefe de Gobierno, siendo suficiente, para ello, por ejemplo, la simple ineptitud del Primer-Ministro, el incumplimiento por su parte de un acuerdo político previo, la pérdida de apoyo de la mayoría parlamentaria, o incluso la práctica de un acto privado considerado indiscreto y violador de "buenas

39 Sunstein, (2017), pp. 14-15.

40 Es una cuestión de pertenencia y de reconocimiento de la Constitución por la sociedad, y por eso la Constitución no puede ser utilizada para fundamentar decisiones que van en contra de procesos democráticos, siendo esto algo muy excepcionalmente admitido (Cf. Post y Siegel (2009), p. 167). 
costumbres". ${ }^{41}$ Por lo tanto, no hay como poner lado a lado el impeachment y el voto de desconfianza.

En este sentido, tampoco la regularidad del procedimiento del impeachment puede legitimar su origen, cuando este no cuenta con apoyo constitucional. El mero respeto a las reglas procedimentales no tiene la prerrogativa de legitimar constitucional y democráticamente -, el resultado del juicio político, siendo este un objeto de constante conflicto entre constitucionalismo y democracia. Aunque ante un contexto de apoyo popular (algo de difícil análisis, considerando los factores que involucran el tema, como la actuación de los medios de comunicación y la propia articulación política alrededor del momento), este no debe ser considerado como una razón para el accionamiento del mecanismo de impeachment, porque dicho instituto consta en la Constitución como manera de proteger el orden constitucional y sus instituciones, no para responder a los vientos sociales eventualmente inestables y frustrados con un determinado gobierno. La revisión del resultado de las urnas debe venir por medio democráticamente legítimo, es decir, por elecciones convocadas y dentro del marco legal, transfiriendo nuevamente al electorado la opción por el mantenimiento del gobierno o no en el poder.

A propósito, merece aquí mención la posición de Pérez-Liñan de que el impeachment presidencial en América Latina emergió en los últimos años como un poderoso instrumento para la destitución de presidentes "indeseables", sin que se destruya el orden constitucional. Sin embargo, el autor afirma que ni siempre la oposición o políticos opositores son capaces de desencadenar un proceso de impeachment en contra del Ejecutivo principal, obligándolos a que se unan a los medios para la exposición de escándalos políticos y para dictar el discurso de retirada del presidente, así como habiendo también un jefe del Ejecutivo que haya perdido el control rígido sobre el Congreso, sea porque su partido es muy pequeño, sea porque está bajo el control de un grupo adversario. Al mismo tiempo, la capacidad del Legislativo de remover el presidente, en último análisis, depende del grado de movilización popular en contra del gobierno..$^{42}$ Cuando una amplia coalición social toma las calles para exigir la renuncia del presidente, la caída de la administración es generalmente un destino casi cierto. ${ }^{43}$

41 Sartori, (2003), pp. 109 y ss.; Moraes y Sobrinho, (2016).

42 Hochstetler, (2006).

43 Pérez-Liñan, (2007), pp. 5-6. 
Sin embargo, aunque haya movilización, aun así habrá un efecto contramayoritario sobre el resultado de las urnas que eligieron el presidente que está a punto de ser destituido. La opinión pública, movilizaciones populares, etc., no tienen como conceder legitimidad democrática a la consolidación de un impeachment cuando éste no está de acuerdo con el marco constitucional.

\section{Algunas conclusiones}

Ante esta exposición, como algunas conclusiones, se puede afirmar que los juicios políticos pueden afectar los derechos políticos de un mandatario elegido democrática y constitucionalmente cuando dichos procesos tienen origen y motivación al margen de la Constitución, es decir, cuando tienen fundamentación meramente política.

El hecho de que un presidente de un país de gobierno presidencialista esté aplicando una agenda que frustre las expectativas de sus votantes; que no atienda a la coalición construida para viabilizar la gobernabilidad o incluso que demuestre no ser capaz políticamente de ejercer sus funciones no lo hace un agente que deba ser destituido por mecanismos como el impeachment. Se defiende, así, que no hay como equiparar el juicio político - algo fundado en la Constitución del inicio al fin, entre contenido, motivación y procedimiento -, con el voto de desconfianza parlamentaria ${ }^{44}$, ya que este tiene previsiones constitucionales de existencia y de posibilidad, pero no es regido por reglas objetivas de ejecución material.

Aún, debido al hecho de que tanto el presidente como el Congreso tener legitimidad democrática, todos los ocupantes de estos cargos tienen especial protección de sus derechos políticos, no debiendo estar condicionados en su actuación sino solamente por el ordenamiento constitucional. Los resultados venidos desde la libertad en el ejercicio de mandato no pueden ser objeto de evaluación por medio de controles políticos de perfil parlamentario, considerando que esto va en contrario a la lógica del sistema presidencialista y sacrifica la mayoría de los votos que eligió el presidente.

Por otro lado, la utilización de mecanismos como el de impeachment debe ser lo más excepcional posible, justamente porque tiene la función de defender la Constitución, la figura del presidente (no la persona), así como el resultado en las urnas. Cualquier uso político de este instrumento puede ser la apertura para

44 Moraes y Sobrinho, (2016). 
eventos no democráticos en un sistema específico. Esta puede ser una de las hipótesis de violación de los derechos políticos del presidente elegido, a la luz del art. 23 de la Convención Americana, y del art. XX de la Declaración Americana de Derechos Humanos, ya que la persona es acusada, por motivos políticos, de una conducta que no fundamenta un juicio político, estando al margen de la Constitución. La persona se ve impedida de ejercer su mandato, democráticamente concedido a ella, bloqueada, por lo tanto, de participar en la dirección de los asuntos públicos directamente, tal y como consta en el art. 23, a, del Pacto de San José.

Se puede, además, afirmar que, si antes las democracias latinoamericanas tenían como final de sus conflictos entre Ejecutivo-Legislativo un golpe militar, actualmente esto fue sustituido por el impeachment, tomado como "procedimiento estándar", que también puede llevar a colapsos democráticos tanto como el primero. ${ }^{45}$ Aun así, se entiende que dichos juicios políticos no pueden ser automáticamente clasificados como "golpes parlamentarios", debido a la atención que se tiene que tener con el empleo del concepto más allá de su tradicional significado.

De esta forma, por más que se aborde el tema de la parlamentarización de los sistemas presidencialistas en América Latina, dicho proceso de racionalización no puede ser un canal de violación de derechos políticos de aquellos que ejercen el cargo de presidente, elegidos democráticamente. Medidas que objetiven el mejor funcionamiento de un sistema político no puede, de ninguna manera, sacrificar derechos, ya que esto hace que se incumpla los propios cánones de la democracia.

\section{Bibliografía citada}

Abranches, Sergio (2018). Presidencialismo de Coalizão: Raízes e Evolução do Modelo Político Brasileiro. (São Paulo, Companhia das Letras).

Amaya, Jorge Alejandro (2016). “Tensiones entre decisiones de los órganos del Sistema Interamericano de Derechos Humanos y el derecho interno de los Estados en materia de derechos políticos", en Lex (n ${ }^{\circ} 18$, año XIV), pp. 19-33. Amaya, Jorge Alejandro; Loianno, Adelina (2014). "Derechos Políticos y medidas cautelares de la CIDH: reflexiones e interrogantes del caso 'Gustavo Petro'”, en Revista Iberoamericana de Derecho Procesal Constitucional ( $\mathrm{n}^{\circ} 21$, ene./ jun.), pp. 295-321.

45 PÉreZ-Liñan, (2007), pp. 5-6. 
Carey, John M. (2008). "Presidential versus Parliamentary Government". en Menard, Claude; Shirley, Mary M. (Eds.). Handbook of new institutional economics. (Heidelberg, Springer), pp. 91-121.

Carpizo, Jorge (2006). "Características esenciales del sistema presidencial e influencias para su instauración en América Latina”, en: Boletín Mexicano de Derecho Comparado (año XXXIX, núm. 115), pp. 57-91.

Correia, Helder Felipe Oliveira; TeiXeira, João Paulo Allain (2018). "O presidencialismo brasileiro nos trinta anos da Constituição Federal de 1988” en Conci, Luiz Guilherme Arcaro; Figueiredo, Marcelo (Coords.), 30 anos da Constituição: múltiplos olhares sobre as suas promessas. (Rio de Janeiro, Lumen Juris), pp. 65-80.

Dworkin, Ronald. 1999. "A Kind of Coup". En The New York Review of Books (14. Ene.). [fecha de consulta: o9 julio de 2020] [Disponible en: http://bit. ly/2MDV8Qw]

Gordillo, Agustín (2017). Tratado de Derecho Administrativo y obras selectas. Tomo 1 (Parte General). (Buenos Aires, Fundación de Derecho Administrativo). [fecha de consulta: o1 octubre de 2019] [Disponible en: http://www.gordillo.com/pdf_tomo1/tomo1.pdf]

HäBerle, Peter (2002). Hermenêutica Constitucional: a sociedade aberta dos intérpretes da Constituição: contribuição para a interpretação pluralista e 'procedimental' da Constituição (Sergio Antonio Fabris Editor, Porto Alegre).

HeLmKe, Gretchen (2017). Institutions on the edge: the origins and consequences of inter-branch crises in Latin America. (UK, Cambridge University Press).

Hochstetler, Kathryn (2006). "Rethinking presidentialism: challenges and presidential falls in South America” en Comparative Politics (jul), pp. 401-418. Huntington, Samuel P. (1992). The Third Wave: Democratization in the Late Twentieth Century. (US, University of Oklahoma Press).

La Palombara, Joseph (1974). Politics Within Nations. (New Jersey, Prentice-hall). Linz, Juan J. (1994). "Presidential or Parliamentary Democracy: Does it Make a Difference" en Linz, Juan J.;Valenzuela, Arturo (eds.). The failure of Presidential Democracy. Comparative Perspectives, v. 1. (Baltimore: The Johns Hopkins University Press), pp. 3-87.

Moraes, Filomeno; Sobrinho, Luís Lima Verde (2016). “Quedas democráticas de governo: o impeachment no presidencialismo brasileiro comparado ao voto 
de desconfiança nos sistemas parlamentaristas", en Revista direitos fundamentais e democracia, (v. 21, n. 21), pp. 45-71.

Nogueira Alcalá, Humberto (1985). "El presidencialismo en la práctica política”, en Nueva Sociedad (n. 77), pp. 88-98.

PÉreZ-Liñan, Aníbal (2007). Presidential impeachment and the new political instability in Latin America. (UK: Cambridge University Press).

PÉrez-Liñan, Aníbal (2009). Juicio político al presidente y nueva inestabilidad política en América Latina. (Buenos Aires: Fondo de Cultura Económica).

PÉREZ-LiÑAn, Aníbal (2011). "Crisis presidenciales: gobernabilidad y estabilidad democrática en América Latina, 1950-1996”, en Revista Instituciones y Desarrollo, (no 8 y 9), pp. 281- 298.

PÉrez-LiÑAN, Aníbal (2018). "Impeachment or Backsliding? Threats to democracy in the twenty-first century" en Revista Brasileira de Ciências Sociais (v. 33 $\mathrm{n}^{\circ}$ 98), pp. 1-15.

Perlingeiro, Ricardo (2018). "Impeachment e devido processo legal” en Revista de Investigações Constitucionais, (v. 5, $\mathrm{n}^{\circ}$ 1), pp. 151-167.

Post, Robert C.; Siegel, Reva B. (2009). "Democratic Constitutionalism". en: Balkin, J. M.; Siegel, R. B. The Constitution in 2020. (Oxford: Oxford University Press), pp. 25-34.

SARtori, Giovanni (2003). Ingeniería constitucional comparada $\cdot 3^{\circ}$ ed. (México, Fondo de Cultura Económica).

Serrafero, Mario D. (1996). "El "Impeachment” en America Latina: Argentina, Brasil Y Venezuela”, en Revista de Estudios Políticos (Nueva Época) ( ${ }^{\circ}$ 92), pp. 137-162.

SCHIER, Paulo Ricardo (2016a). Presidencialismo de coalizão: contexto, formação e elementos na democracia brasileira. (Curitiba, Juruá).

Schier, Paulo Ricardo (2016b). "Presidencialismo de coalizão: democracia e governabilidade no Brasil”, en Revista direitos fundamentais e democracia. (v. 20, n. 20), pp. 253-299.

Sunstein, Cass (2017). Impeachment. A citizen's guide. (Cambridge, Harvard University Press).

Tavares, André Ramos (2016). Curso de Direito Constitucional. $14^{\circ}$ ed. (São Paulo, Saraiva).

VAladÉs, Diego (2005). El control del poder (Buenos Aires, Ediar). 
VAlAdÉs, Diego (2011). La parlamentarización de los sistemas presidenciales. $2^{\circ}$ ed. (Ciudad de México, UNAM).

ZúÑIga Urbina, Francisco (1993). “Acusación en juicio político: notas sobre la justicia política” en Revista Chilena de Derecho (v. 20, n. 2/3), pp. 705-724.

ZúñIga Urbina, Francisco (2006). "Responsabilidad Constitucional del Gobierno" en Ius et Praxis (v. 12, n. 2), pp. 43-74.

ZúÑga Urbina, Francisco (2019). "Presidencialismo en América Latina puesto a prueba por el impeachment o golpe de Estado parlamentario y por el continuismo o reeleccionismo presidencial en vía judicial" en Gajardo Falcón, Jaime; Zúñiga Urbina, Francisco (Coords.). Constitucionalismo y procesos constituyentes. Una revisión crítica al nuevo constitucionalismo latinoamericano. v. 2. (Santiago, Thompson Reuters), pp. 153-186. 
